\title{
PERSEPSI SISWA TERHADAP PEMANFAATAN LABORATORIUM VIRTUAL DALAM PEMBELAJARAN FISIKA TOPIK GERAK LURUS (SURVEY TERHADAP SISWA KELAS X SMAN 87 JAKARTA SELATAN)
}

\author{
Heni Safitri (henip@ut.ac.id) \\ Herawati \\ FKIP-UT, Jl. Cabe Raya, Pondok Cabe, Pamulang, Kota Tangerang Selatan
}

\begin{abstract}
ABSTRAK
Experiment is the core of physics subject. Most of physics phenomena taught in school, are not based on observation. They are taught verbally and in few cases they are correlated with phenomena found in daily life. The presence of virtual laboratory could solve the problems as well as provide alternative solution for lack of equipments of physics laboratory in most schools. This research explained the perception of students about utilization of virtual laboratory in physics to learn the topic of linear motion. The research carried out on student class X in SMAN 87 Jakarta Selatan in 2009/2010. Data is collected from quesioner and then analyzed descriptively. The result indicates that using virtual laboratory, students better understand the concept of linear motion and give them experience of more save and more compartable practicum.
\end{abstract}

Keywords: straight motion topic, student perception, virtual laboratories

Pemanfaatan Laboratorium virtual bukan untuk menggantikan peran laboratorium yang sebenarnya (laboratorium riil), namun sebagai alternatif solusi atas minimnya peralatan laboratorium fisika yang sesungguhnya di sekolah-sekolah. Eksperimen adalah bagian utama dalam pembelajaran fisika. Dengan kegiatan eksperimen siswa mendapatkan pengalaman inquiri dan menemukan pengetahuan yang dicari. Melalui pemanfaatan laboratorium virtual fisika ini siswa dapat melakukan kerja ilmiah, melalui interaksi dengan program fisika siswa akan semakin meningkat pemahamannya terhadap konsep fisika. Laboratorium virtual yang berperan sebagai produk teknologi bertujuan untuk mengantarkan siswa agar memiliki pengetahuan, keterampilan, dan sikap yang berkaitan erat dengan proses dan produk teknologi (Budiastra: 2004). Lebih lanjut, menurut Asriyanto (2007) melalui laboratorium virtual siswa diharapkan lebih termotivasi untuk melakukan pengamatan dan percobaan fisika, siswa dapat menjadikan laboratorium virtual fisika sebagai sarana menemukan konsep-konsep fisika yang lebih menyenangkan dan dapat divisualisasikan sehingga tidak hanya menjadi imajinasi belaka, motivasi siswa meningkat untuk lebih mempelajari topik-topik fisika serta terbentuknya pembelajaran yang menyenangkan dalam suasana belajar.

Banyak keuntungan diperoleh dari penggunaan media komputer sebagai alat bantu pembelajaran. Jackson (dalam Paramata, 1996) menyatakan bahwa pengajaran yang menggunakan komputer dapat mengembangkan keterampilan berpikir siswa. Selain itu penggunaan media komputer dapat menyeimbangkan kebutuhan waktu dan keperluan pemrosesan dari tugas-tugas tertentu, serta memungkinkan pengembangan pendekatan pembelajaran bervariasi.

Menurut Hamalik (2001) komputer adalah suatu medium interaktif, dimana siswa memiliki kesempatan untuk berinteraksi dalam bentuk mempengaruhi atau mengubah urutan yang disajikan sehingga meningkatkan motivasi dan memberikan pengalaman kinestetik melalui penggunaan 
keyboard komputer. Polla (2000) menyatakan pembelajaran berbantuan komputer mampu menciptakan suatu proses belajar mengajar yang interaktif, sehingga dapat memberikan manfaat optimal bagi siswa dan guru dalam mencapai tujuan pendidikan. Defrianto (2001) mencoba menggunakan metode pengajaran fisika interaktif dan visualisasi komputer dan hasilnya memberikan kenaikan nilai rata-rata yang signifikan.

Puspita dan Yamin (2008) memberikan definisi laboratorium virtual merupakan sistem yang dapat digunakan untuk mendukung sistem praktikum yang berjalan secara konvensional. virtual laboratory ini biasa disebut dengan virtual-lab. Panner (2001) menyatakan bahwa "The Virtual Laboratory is an interactive environment for creating and conducting simulated experiments: a playground for experimentation. It consists of domain-dependent simulation programs, experimental units called objects that encompass data files, tools that operate on these objects".

Tujuan penelitian ini adalah untuk mendeskripsikan persepsi siswa terhadap pemanfaatan laboratorium virtual pada topik gerak lurus.

Penelitian dilakukan di Sekolah Menengah Atas Negeri 87. Pemilihan lokasi dipertimbangkan atas dasar sekolah SMAN 87 Jaksel menjadi sekolah mandiri untuk melakukan suatu metode pembelajaran yang baru dengan memanfaatkan teknologi informasi yang salah satunya adalah pemanfaatan laboratorium virtual. Siswa kelas X semester I Tahun ajaran 2009/2010 diberi pelajaran fisika dengan topik gerak lurus. Jumlah subjek penelitian 30 siswa. Setelah siswa menggunakan laboratorium virtual topik gerak lurus dengan menggunakan ticker timer siswa diberi kuesioner berisi 12 item pernyataan tentang persepsi terhadap pembelajaran fisika topik gerak lurus dalam bentuk skala likert dengan kisaran 5 skala (sangat tidak setuju, tidak setuju, ragu-ragu, setuju dan sangat setuju) serta 2 pertanyaan bebas dalam bentuk uraian tentang keefektifan penggunaan laboratorium virtual dalam pembelajaran fisika. Data yang terkumpul dianalisis menggunakan pendekatan deskriptif dan data disajikan dalam bentuk persentase.

\section{HASIL DAN PEMBAHASAN}

Penggunaan Laboratorium virtual fisika diharapkan dapat meningkatkan motivasi siswa dalam mengikuti pembelajaran fisika. Selain itu, melalui penggunaan laboratorium virtual siswa diharapkan dapat menikmati dan tidak merasa bosan dalam mengikuti pembelajaran fisika. Hal ini ditunjukkan melalui data berikut yang menggambarkan persepsi siswa terhadap penggunaan laboratorium virtual dalam pembelajaran fisika seperti data yang terlihat pada Gambar 1 berikut.

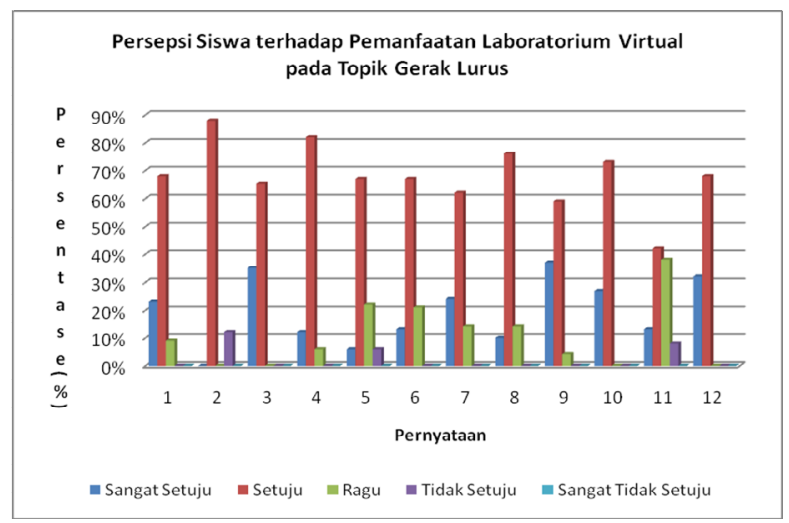

Gambar 1. Persepsi siswa tentang penggunaan laboratorium virtual terhadap pemahaman topik gerak lurus 
Gambar tersebut memperlihatkan sebagian besar siswa (antara 42\% - 88\%) setuju tentang penggunaan laboratorium dalam pembelajaran di kelas. Pernyataan setuju tersebut meliputi 12 item seperti Tabel 1.

\section{Tabel 1. Pernyataan Persepsi Siswa tentang Penggunaan Laboratorium Virtual Terhadap} Pemahaman Topik Gerak Lurus

\section{Pernyataan Siswa}

Saya dapat menggunakan program virtual lab tentang topik GLB dan GLBB

Saya banyak belajar tentang konsep gerak lurus dengan menggunakan lab virtual

Saya lebih mengerti melakukan praktikum dengan menggunakan lab virtual

Saya lebih mengerti tentang konsep gerak lurus dengan menggunakan lab virtual

Saya lebih mudah mengerti penjelasan guru dengan menggunakan lab virtual

Saya lebih mudah mempersiapkan praktikum dengan menggunakan lab virtual

Saya lebih mudah mengambil data praktikum dengan menggunakan lab virtual

Saya lebih mudah menganalisis hasil praktikum dengan menggunakan lab virtual

Saya lebih aman menggunakan lab virtual

Saya merasa lebih cepat melaksanakan praktikum dengan menggunakan lab virtual

Saya merasa lebih sedikit mengalami stress pada saat menggunakan lab virtual

Saya lebih suka/menikmati menggunakan lab virtual sebagai cara dalam melaksanakan praktikum fisika

karena mudah mengoperasikannya

Dari pernyataan di atas, sebanyak 35\% siswa menyatakan sangat setuju dapat menggunakan program lab virtual tentang topik GLB dan GLBB, sedangkan sebanyak 88\% siswa setuju bahwa mereka banyak belajar tentang gerak lurus dengan menggunakan lab virtual, 82\% siswa setuju bahwa mereka lebih mengerti tentang konsep gerak lurus dengan menggunakan lab virtual dan sebanyak 67\% siswa menyatakan setuju bahwa mereka lebih mudah mengerti penjelasan guru dengan menggunakan laboratrium virtual. Sementara itu, 68\% siswa menyatakan setuju bahwa mereka lebih suka/menikmati menggunakan lab virtual sebagai cara dalam melaksanakan praktikum fisika karena mudah mengoperasikannya.

Pernyataan secara kuantitatif tersebut diperkuat dengan ungkapan siswa tentang keefektifan pembelajaran fisika dengan menggunakan laboratorium virtual fisika seperti tergambar pada Tabel 2 berikut ini.

Tabel 2. Pendapat Siswa tentang Kefektifan Kegunaan Laboratorium Virtual pada Pembelajaran Fisika

\begin{tabular}{l} 
Pernyataan Siswa \\
\hline Virtual lab, karena gampang untuk dimengerti dan mudah menjelaskan \\
Virtual lab, karena lebih gampang dimengerti dan lebih mudah untuk melakukan percobaan \\
Virtual lab, karena bisa menempuh waktu yang sedikit dan kita hanya duduk dan mengoperasikan komputer untuk \\
laptop saja \\
Tidak, karena lab virtual keprakteknya tidak langsung.jadi kita tidak mencobanya jadi tidak bisa mengerti. \\
Virtual lab. karena cara mengoperasikannya lebih mudah dan tidak perlu menghitung jarak dan waktunya lagi. \\
Virtual lab, karena lebih mudah mengoperasikannya dan lebih cepat melaksanakan praktikum dan menggunakan \\
$\quad$ virtual lab. \\
Menurut saya lebih efektif virtual lab karena dengan cara ini lebih mudah dan cepat prosesnya. \\
Virtual lab karena prakteknya lebih simpel. \\
Virtual lab karena lebih mudah,simpel dan praktis \\
Tidak, karena bingung mengerjakannya \\
Lab virtual,karena lebih terasa gampang/tidak terlalu sulit
\end{tabular}


Tabel 2. (Lanjutan)

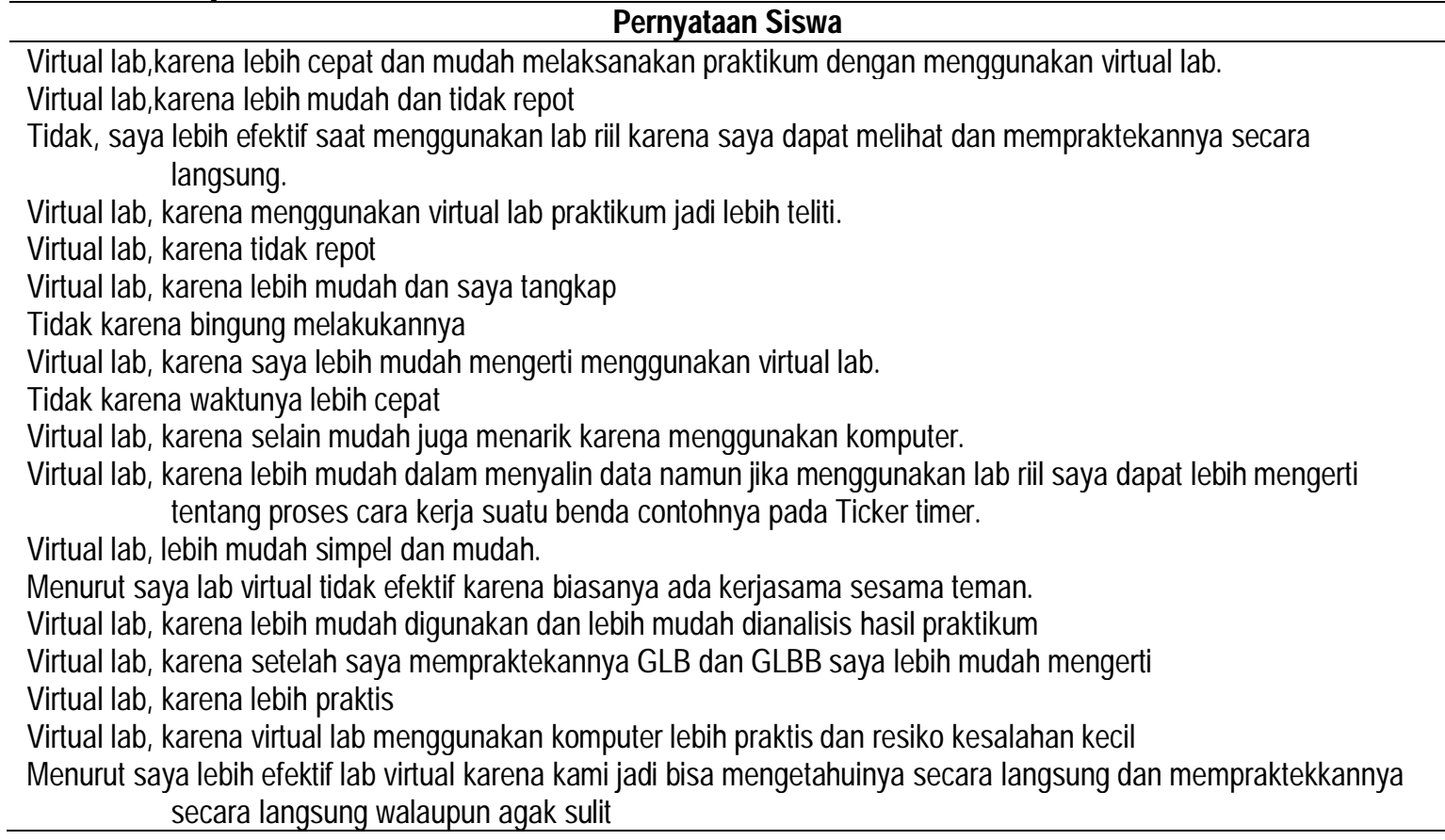

Berdasarkan pernyataan 30 orang siswa (satu orang tidak menjawab), hanya 17\% siswa yang menyatakan bahwa penggunaan laboratorium virtual tidak efektif bagi pembelajaran fisika, dikarenakan siswa merasa dengan menggunakan laboratorium virtual kurang terjadi kebersamaan atau kerjasama dalam kelompok. Selain itu siswa belum terbiasa melakukan praktikum dengan laboratorium virtual dalam pembelajaran. Sedangkan $83 \%$ siswa lainnya menyatakan bahwa laboratorium virtual sangat efektif untuk pembelajaran fisika di kelas, dengan alasan: laboratorium virtual mudah untuk dimengerti dan mudah untuk menjelaskan, pelaksanaan praktikum menjadi lebih cepat, lebih praktis dan lebih sederhana.

\section{KESIMPULAN DAN SARAN}

Persepsi siswa terhadap pemanfaatan laboratorium virtual untuk topik gerak lurus mendapatkan respon positif siswa. Penggunaan dalam penggunaan laboratorium virtual tentang peningkatan pemahaman dan pengalaman belajar fisika terutama tentang praktikum gerak lurus yang menggunakan ticker timer. Hal tersebut diperkuat dengan pernyataan siswa yang sebagian besar mengungkapkan setuju menggunakan laboratorium virtual dan siswa lebih mengerti konsep gerak lurus dengan menggunakan laboratorium virtual.

Penggunaan laboratorium virtual merupakan hal yang positif karena menumbuhkan minat dan menghindarkan siswa dari kejenuhan. Siswa selalu membutuhkan hal-hal yang baru, menarik, dan dapat di nikmati ketika siswa sedang belajar. Selain itu, pembelajaran yang menggunakan laboratorium virtual mampu memberikan variasi-variasi dalam proses pembelajaran fisika, karena laboratorium dapat menggambarkan secara visual langkah-langkah praktikum dan pengambilan data praktikum secara cepat. 


\section{REFERENSI}

Asriyanto. (2007). Senangnya eksperimen di laboratorium virtual fisika. Jakarta: ITSF.

Budiastra, K.A.A. (2004). Laboratorium kering dan laboratorium basah. Jakarta: Universitas Terbuka.

Defrianto. (2001). Perbaikan Proses Pembelajaran Mata Kuliah Mekanika Klasik dengan

Menggunakan Metode Belajar Interaktif dan Visualisasi Komputer. Prosiding seminar dan

lokakarya pembelajaran di perguruan tinggi, Bandar Lampung: Universitas Lampung.

Hamalik, O. (2001). Proses Belajar Mengajar. Jakarta: Bumi Aksara.

Panner, J. (2001). http://pages.cpsc.ucalgary.ca/ pwp/bmv/vlab-for-linux/html-docs/environment.html

Paramata, Y. (1996). Computer aided instruction (CAI) dalam pembelajaran IPA-Fisika. Tesis pada PPS IKIP Bandung. Tidak diterbitkan.

Puspita, R. \& Yamin, M. (2008). Proceeding. Seminar Ilmiah Nasional Komputer dan Sistem Intelijen. Jakarta.

Polla, G. (2000). Buletin Pelangi Pendidikan. Jakarta: UNJ. 